\title{
LA PRUEBA TESTIFICAL ANTICIPADA COMO INSTRUMENTO PARA REDUCIR LA VICTIMIZACIÓN SECUNDARIA DE MENORES DE EDAD EN EL PROCESO PENAL
}

\author{
Diana Marrero Guanche* \\ Contratada predoctoral FPI \\ Universidad de La Laguna
}

\section{RESUMEN}

En este artículo se estudia la creciente importancia del riesgo de victimización secundaria tanto en la normativa nacional como en la supranacional. Asimismo, se examina cómo esta preocupación ha provocado la regulación de especialidades en las declaraciones sumariales de las víctimas menores de edad, por ejemplo, a través de la Ley 4/2015, de 27 de abril, del Estatuto de la víctima del delito o, más recientemente, la Ley 8/2021, de 4 de junio, de protección integral a la infancia y la adolescencia frente a la violencia. Finalmente, se analiza en qué medida las modificaciones efectuadas para evitar la victimización secundaria han afectado al principio de contradicción y al derecho a la presunción de inocencia.

Palabras Clave: victimización secundaria, principio de contradicción, prueba anticipada, declaración sumarial, víctimas de delitos.

\section{THE EVIDENCE PRIOR TO TRIAL AS AN INSTRUMENT \\ TO AVOID THE RISK OF SECONDARY VICTIMATION \\ OF UNDERAGE VICTIMS IN CRIMINAL PROCEEDINGS}

\section{Abstract}

This article studies the growing importance of the risk of secondary victimization in both national and supranational legislation. It also examines how this concern has led to the regulation of specialties in the statements of underage victims at the pre-trial stage, for example, through Law 4/2015, of April 27, on the Statute of the victim of crime or, more recently, Law 8/2021, of June 4, on the comprehensive protection of children and adolescents against violence. Finally, it is analyzed to what extent the modifications made to avoid secondary victimization have affected the principle of contradiction and the right to the presumption of innocence.

KEYWORDS: secondary victimization, adversarial principle, evidence prior to trial, statements at the pre-trial stage, victims of crimes. 


\section{INTRODUCCIÓN}

En España preocupa el número de delitos contra la libertad e indemnidad sexuales y, sobre todo, los casos en los que las víctimas de estos delitos son menores de edad, pues, según el informe sobre delitos contra la libertad e indemnidad sexual emitido por el Ministerio del Interior del Gobierno de España, en el año 2019 el $46,2 \%$ de este tipo de delitos se cometió contra una víctima menor de edad ${ }^{1}$.

La ejecución de este tipo de delitos causa a las víctimas -especialmente a los menores de edad-daños tanto físicos como psicológicos ${ }^{2}$. A estos perjuicios provocados por la comisión del hecho delictivo se suman también los efectos negativos que sufre la víctima como consecuencia de sus relaciones con los agentes de la policía o la administración de justicia; en definitiva, la denominada victimización secundaria.

La pregunta que se plantea en relación con la victimización secundaria es la siguiente: ¿`cómo pueden reducirse los daños que sufren los menores en sus relaciones con la administración de justicia?

En esta ocasión, a pesar de la importancia que el uso de la inteligencia artificial ha alcanzado en la solución de los problemas que plantea el proceso penal ${ }^{3}$, la respuesta no la encontramos en el uso de ninguna tecnología revolucionaria. Aunque es cierto que, como se analizará en líneas posteriores de este trabajo, los medios de grabación de sonido e imagen tienen un papel importante en la protección de los menores, pero más allá de estos medios tecnológicos parece que debe prestarse especial atención al factor humano.

La respuesta a la anterior pregunta podemos encontrarla en la práctica de la prueba testifical anticipada como instrumento para reducir la victimización secundaria. Como es sabido, en la LECrim se permite anticipar la realización de la prueba cuando se presuma que los testigos o peritos no podrán estar presentes en el acto del juicio oral ${ }^{4}$. Pues bien, la preocupación por reducir la victimización secundaria

* Trabajo realizado en el ámbito de un contrato predoctoral de formación del personal investigador concedido por la Consejería de Economía, Conocimiento y Empleo del Gobierno de Canarias, cofinanciado por el Fondo Social Europeo.

${ }^{1}$ El 15,9\% de las víctimas de este tipo de delitos tienen entre 0 y 13 años, mientras que el 17,5\% tiene entre 14 y 17 años. Puede consultarse en https://bit.ly/3sqHZgj (último acceso: $11 \mathrm{de}$ marzo de 2021).

${ }^{2}$ Para hacer referencia a estos daños se utiliza la expresión victimización primaria.

3 Bueno de Mata, F., «Macrodatos, inteligencia artificial y proceso: luces y sombras», en Revista General de Derecho Procesal, n. ${ }^{\circ}$ 51, 2020; BARona Vilar, A., "Cuarta revolución industrial (4.0) o ciberindustria en el proceso penal: revolución digital, inteligencia artificial y el camino hacia la robotización de la justicia», en revista jurídica digital UANDES, n. ${ }^{\circ} 1,2019$. El Ministerio de Justicia español ha valorado contratar un deep learning -o sistema de inteligencia artificial de caja negra- denominado Prometea. Véase el artículo periodístico «La justicia artificial se asoma a la justicia pero despierta dudas éticas» en la revista Retina del periódico El País. Puede consultarse en el siguiente enlace: https://bit.ly/3tbwoSs (último acceso: 25 de marzo de 2021).

${ }^{4}$ Artículo 448 párrafo $1 .^{\circ}$ LECrim: «Si el testigo manifestare, al hacerle la prevención referida en el artículo 446, la imposibilidad de concurrir por haber de ausentarse del territorio nacional, y también en el caso en que hubiere motivo racionalmente bastante para temer su muerte o inca- 
de los menores ha provocado que también pueda procederse a la anticipación de las declaraciones de los menores, a pesar de que, como se analizará en este trabajo, en rigor, no estemos ante un hecho irrepetible .

Por todo ello, resulta de especial interés el estudio de la prueba testifical anticipada como instrumento para reducir el riesgo de victimización secundaria de los menores, así como su regulación en el Anteproyecto de Ley de Enjuiciamiento Criminal aprobado por el Consejo de Ministros el 24 de noviembre de 2020 (en adelante APLECrim 2020). Asimismo, recientemente ha entrado en vigor la Ley Orgánica 8/2021, de 4 de junio, de protección integral a la infancia y la adolescencia frente a la violencia (en lo sucesivo LOPIIA), que ha modificado la regulación de la prueba testifical anticipada y ha establecido como excepcional la declaración en juicio de los menores de catorce años o personas con discapacidad necesitadas de especial protección ${ }^{6}$.

\section{LA VICTIMIZACIÓN SECUNDARIA}

La Real Academia Española define el término victimización como la «acción de victimizar" y el verbo victimizar como "convertir en víctimas a personas o animales». La victimización, desde un punto de vista jurídico, hace referencia no sólo al

pacidad física o intelectual antes de la apertura del juicio oral, el Juez instructor mandará practicar inmediatamente la declaración, asegurando en todo caso la posibilidad de contradicción de las partes. Para ello, el Secretario judicial hará saber al reo que nombre abogado en el término de veinticuatro horas, si aún no lo tuviere, o de lo contrario, que se le nombrará de oficio, para que le aconseje en el acto de recibir la declaración del testigo. Transcurrido dicho término, el Juez recibirá juramento y volverá a examinar a éste, a presencia del procesado y de su abogado defensor y a presencia, asimismo, del Fiscal y del querellante, si quisieren asistir al acto, permitiendo a éstos hacerle cuantas repreguntas tengan por conveniente, excepto las que el Juez desestime como manifiestamente impertinentes».

5 Todo lo más podríamos decir que nos encontramos ante una imposibilidad objetiva impuesta por el legislador para salvaguardar el interés del menor. Véase Serrano Masip, M., «La incorporación al proceso penal español de la normativa UE sobre el interrogatorio o la exploración de la víctima menor de edad", en Delitos contra la libertad e indemnidad sexual de los menores, Aranzadi, Navarra, 2015, p. 540.

${ }^{6}$ Párrafos 39 y 40 del apartado II del Preámbulo de la LOPIIA: «En relación con la prueba preconstituida es un instrumento adecuado para evitar la victimización secundaria, particularmente eficaz cuando las víctimas son personas menores de edad o personas con discapacidad necesitadas de especial protección. Atendiendo a su especial vulnerabilidad se establece su obligatoriedad cuando el testigo sea una persona menor de catorce años o una persona con discapacidad necesitada de especial protección. En estos supuestos la autoridad judicial, practicada la prueba preconstituida, solo podrá acordar motivadamente su declaración en el acto del juicio oral, cuando, interesada por una de las partes, se considere necesario. Por tanto, «se convierte en excepcional la declaración en juicio de los menores de catorce ańos o de las personas con discapacidad necesitadas de especial protección", estableciéndose como norma general la práctica de la prueba preconstituida en fase de instrucción y su reproducción en el acto del juicio evitando que el lapso temporal entre la primera declaración y la fecha de juicio oral afecten a la calidad del relato, así como la victimización secundaria de víctimas especialmente vulnerables». 
acto de convertir a una persona en víctima, sino también a las consecuencias negativas que la persona sufre como consecuencia de este proceso.

Gómez Colomer distingue hasta cuatro tipos de victimización, aunque señala que sólo son verdaderamente importantes tres: victimización primaria, secundaria y terciaria ${ }^{7}$. La victimización primaria es la que sufre el sujeto pasivo del delito de forma directa por la ejecución del hecho delictivo: por ejemplo, las lesiones psíquicas que parece se derivan de los delitos de carácter sexual ${ }^{8}$. La victimización secundaria, que será estudiada con más detalle en el epígrafe siguiente, se define como las consecuencias negativas adicionales que puede sufrir la víctima durante la tramitación del proceso penal, desde la investigación policial hasta la sentencia firme. Finalmente, la victimización terciaria estaría constituida por los efectos que padece la sociedad, por ejemplo, el miedo social o la desconfianza hacia la justicia penal'.

\subsection{Concepto}

La Directiva 2012/29/UE ${ }^{10}$ no contiene un concepto de victimización secundaria, a pesar de las referencias que se realizan en la citada norma al riesgo de victimización reiterada que padecen las víctimas y a las medidas que deben adoptar los gobiernos nacionales para evitarlo. Asimismo, la Ley 4/2015, de 27 de abril, del Estatuto de la víctima del delito (en adelante LEVD), que transpone la anterior directiva al ordenamiento jurídico español, tampoco ofrece una definición.

La victimización secundaria se ha definido por la doctrina como aquel proceso por el que, paradójicamente, la persona que ha sufrido el hecho delictivo se

7 Gómez Colomer, J.L., Estatuto Jurídico de la Victima del delito. La posición jurídica de la víctima de delito ante la justicia penal. Un análisis basado en el Derecho comparado y en las grandes reformas españolas que se avecinan, Aranzadi, Navarra, 2014, p. 230.

${ }^{8}$ Sentencia de la Sala Segunda del TS, de 17 de octubre de 2019: «Respecto a las consecuencias de tales actos sufridos por la menor, señalar que la doctrina apunta las dos vías de la victimización primaria. Y, así, se consideran todos aquellos efectos negativos que puede sufrir el menor por la exposición a una situación de victimización sexual. Tradicionalmente se han dividido las repercusiones psicopatológicas asociadas al ASI en dos grupos: consecuencias a corto plazo (en los dos años siguientes a la experiencia de victimización) y consecuencias a largo plazo. Se han detectado -apunta la doctrina-, desajustes en las funciones fisiológicas, en el área cognitiva, emocional, comportamental y relacional de los menores, dependiendo de su etapa evolutiva».

${ }^{9}$ Gómez Colomer introduce en la victimización terciaria los daños ocasionados al infractor. En mi opinión, las consecuencias negativas que la comisión del delito pueda tener para el autor del mismo no deben calificarse como victimización terciaria, porque los daños que puedan producirse se derivan de su actuación antijurídica. Este tipo de victimización es el que más debate doctrinal ha generado en cuanto a su contenido. Gómez Colomer, J.L., Estatuto Jurídico de la Víctima..., cit., pp. 230-231. Véase también Morillas Fernández, D.L., "La victimización penitenciaria», en Revista Internacional de Doctrina y Jurisprudencia, n. ${ }^{\circ}$ 14, 2016.

${ }_{10}$ Adoptada por el Parlamento Europeo y del Consejo el 25 de octubre de 2012. Esta directiva establece normas mínimas sobre los derechos, el apoyo y la protección de las víctimas de delitos, y sustituye la Decisión marco 2001/220/JAI del Consejo. 
convierte en víctima del sistema judicial ${ }^{11}$. Lo habitual es que la victimización secundaria no pueda acreditarse, pues es consecuencia de un trato personal entre el sujeto pasivo del delito y los funcionarios de la administración de justicia o de la policía. Sin embargo, a continuación analizaré brevemente algunos ejemplos de victimización secundaria que podemos encontrar en las resoluciones judiciales.

1. ${ }^{\circ}$ "El caso de la mujer de vida licenciosa» ${ }^{12}$. La sentencia de la Audiencia Provincial de Pontevedra, de 27 de febrero de 1989, absuelve a los procesados por un delito de violación al no apreciar la concurrencia de violencia o intimidación. En la citada sentencia se valoran circunstancias personales de la víctima, como la "vida licenciosa y desordenada» que mantiene, porque se encontraba «sola en una discoteca a altas horas de la madrugada después de haber ingerido bebidas alcohólicas». Asimismo, se cuestiona que la víctima viajase en el «vehículo de unos desconocidos sin la menor oposición», para argumentar la ausencia de violencia o intimidación ${ }^{13}$.

2. El caso de la mujer que se embriaga en compañía de un hombre ${ }^{14}$. A pesar de que puede parecer que estos recelos hacia la víctima quedaron en el pasado siglo, lo cierto es que la sentencia de la Audiencia Provincial de Toledo 29/2010, de 2 de julio, es otro ejemplo de victimización secundaria. Esta resolución cita la sentencia del TS de 3 de diciembre de 1979 que establecía que «si una mujer se embriaga en compañía de un hombre, acepta, en cierto modo, las consecuencias de sus actos, pero que, a pesar de ello, no siempre su embriaguez ha de ser apreciada como prueba de su consentimiento». No sólo impresiona la referencia a la citada sentencia, sino también las manifestaciones que se realizan acerca de que la víctima no se sorprenda de que estaban a solas o las alusiones a que la víctima estaba acostumbrada a ingerir bebidas alcohólicas ${ }^{15}$.

$3 .^{\circ}$ El caso de la joven que se inició en las relaciones sexuales a los 16 años $^{16}$. La argumentación de la sentencia de la Audiencia Provincial de Navarra 38/2018,

11 Morillas Fernández, D.L., Patró Hernández, R.M. y Aguilar Cárceles, M.M., Victimología: un estudio sobre la victima y los procesos de victimización, Dykinson, Madrid, 2014, pp. 115-117.

12 Éste es el título que Landrove Díaz elige para analizar la sentencia de 27 de febrero de 1989, de la Audiencia Provincial de Pontevedra, y que, como él mismo reconoce, recuerda a una fórmula de la literatura policiaca. LANdrove Díaz, G., «La víctima y el juez», en Victimología: VIII Cursos de Verano en San Sebastián, Universidad del País Vasco, 1990, pp. 189-191.

13 Ibidem.

${ }^{14}$ El título de este supuesto sigue la fórmula literaria policíaca escogida en LANDrove Diaz, G., «La víctima y...», cit.

${ }_{15}$ Sentencia de la Audiencia Provincial de Toledo 29/2010, de 2 de julio: «Paula estaba acostumbrada a tomar alcohol, tal vez no en grandes cantidades, pero tampoco era abstemia, y aceptó, incluso antes de ir al piso de Pedro, a tomar caipiriñas».

${ }^{16}$ Aquí también he recurrido a la fórmula literaria policíaca escogida en LANDrove Diaz, G., «La víctima y...», cit. 
de 20 de marzo, gira en torno a la existencia o no de consentimiento por parte de la víctima. No obstante, la polémica no ha tenido su origen en el fallo, sino en el voto particular emitido por uno de los magistrados. Uno de los argumentos del magistrado para mantener su tesis acerca de la existencia de consentimiento es la iniciación de la joven en las relaciones sexuales a los 16 ańos, de modo que entiende el magistrado que la víctima tenía la madurez necesaria para mantener el tipo de relación sexual que decida ${ }^{17}$.

Este sinsentido de los daños que sufre la víctima como consecuencia del funcionamiento de la administración de justicia plantea la duda sobre si la solución a este problema podría venir de la mano de los denominados -desde mi punto de vista, erróneamente ${ }^{18}$ - jueces robot. Sin embargo, además de por lo obvio, pues parece que, como ha señalado Bueno de Mata, debe trazarse una línea roja con el fin de evitar la sustitución del juez por sistemas de inteligencia artificial ${ }^{19}$, debe recordarse que los algoritmos no están exentos de los prejuicios de la sociedad ${ }^{20}$.

Las víctimas de delitos de carácter sexual son especialmente vulnerables a sufrir victimización secundaria no sólo por la naturaleza del hecho delictivo, sino también porque lo habitual en este tipo de delitos es que el único medio de prueba sea la testifical de la víctima. La Sala $2 .{ }^{a}$ del TS ha establecido que el tribunal sentenciador deberá prestar especial atención al testimonio de la víctima y comprobar que no existan razones objetivas que cuestionen su credibilidad. Pues bien, esta cir-

17 Voto particular a la sentencia de la Audiencia Provincial de Navarra 38/2018, de 20 de marzo: «Finalmente, a mi juicio, no puede establecerse como a priori que una joven con edad más cercana a los 19 que a los 18 años e iniciada en las relaciones sexuales a los 16, no esté dotada de suficiente madurez personal como para decidir, con la necesaria autonomía, las relaciones sexuales que quiera mantener, por personalísimas razones que solo le incumben a ella, mucho menos en una sociedad como la actual en la que los individuos, con independencia de su sexo, han alcanzado de hecho un considerable grado de libertad para autodeterminarse sexualmente» (énfasis en cursiva añadido).

${ }^{18} \mathrm{La}$ expresión juez robot hace que pensemos en robot humanoides como los protagonistas de las películas Robocop, Blade Runner o Chappie, también nos recuerda al robot Sophia, creado por el estadounidense David Hanson. Véase la noticia publicada en el periódico El Pais en este enlace: https://bit.ly/3rH4MnP (último acceso: 12 de marzo de 2021). Sin embargo, cuando se hace referencia a los jueces robots en realidad no veremos un robot con forma humanoide y con toga; al contrario, se trata de programas informáticos instalados en un dispositivo electrónico, normalmente un ordenador.

19 Bueno de Mata, F., «Macrodatos, inteligencia artificial...», cit., p. 18.

${ }^{20}$ Borges Blázquez, R., «El sesgo de la máquina en la toma de decisiones en el proceso penal», en IUS ET SCIENTIA: Revista electrónica de Derecho y Ciencia, n. ${ }^{\circ}$ 2, 2020 p. 69, advierte que "predecir el futuro mirando al pasado conlleva el riesgo de que en el futuro se sigan repitiendo los mismos estereotipos de género que vamos superando como sociedad. Debemos ser prudentes no solo en fase de aplicación de la IA, sino ir un paso más allá y preguntarnos quién hay detrás de la máquina, cómo se ha hecho el algoritmo, a quién beneficia y a quién perjudica-consciente o inconscientemente- porque puede acabar por controlar el pensamiento jurídico global». Véase también el artículo publicado en el periódico El Diario titulado "Sesgos de género en los algoritmos: un círculo perverso de discriminación en línea y en la vida». Puede consultarse en https://bit.ly/3etK3A4 (último acceso: 12 de marzo de 2021). 
cunstancia se acentúa más en las declaraciones de víctimas menores de edad, debido a su falta de madurez para afrontar este tipo de situaciones ${ }^{21}$. Por este motivo, la normativa europea se ha preocupado por evitar este riesgo de victimización con especial referencia a las víctimas vulnerables.

\subsection{LA CRECIENTE PREOCUPACIÓN POR EL RIESGO DE VICTIMIZACIÓN SECUNDARIA}

La preocupación europea por la protección de la víctima en el proceso penal se consolida con la Recomendación (85)11, de 28 de junio de 1985, sobre la posición de la víctima en el marco del Derecho penal y del Derecho procesal ${ }^{22}$, y la Decisión Marco 2001/220/JAI, de 15 de marzo de 2001, relativa al estatuto de la víctima en el proceso penal ${ }^{23}$.

A pesar de que estos instrumentos no provocaron la aprobación en España de un estatuto jurídico de la víctima del delito, fomentaron la elaboración de normas que, aunque parcialmente, conformaban un marco normativo garante de los derechos de determinadas víctimas. A modo de ejemplo cabe citar los siguientes textos legales: la Ley Orgánica 19/1994, de 23 de diciembre, de protección a testigos y peritos en causas criminales; la Ley 35/1995, de 11 de diciembre, de ayudas y asistencia a las víctimas de delitos violentos y contra la libertad sexual; la Ley Orgánica 1/1996, de 15 de enero, de protección jurídica del menor; la Ley Orgánica 1/2004, de 28 de diciembre, de medidas de protección integral contra la violencia de género; y la Ley 29/2011, de 22 de septiembre, de reconocimiento y protección integral a las víctimas del terrorismo.

En el año 2009 la Comisión Europea emitió un informe en el que se destaca que ningún Estado miembro había aprobado una única norma reguladora de los derechos de las víctimas ${ }^{24}$. Por este motivo se dictó la Directiva 2012/29/UE para otorgar carácter obligatorio a las disposiciones de la Decisión marco 2001/220/JAI, así como para mejorar la protección de las víctimas en los estados de la Unión. Precisamente este interés por mejorar la defensa de las víctimas supuso que la Directiva

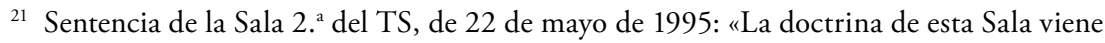
acogiendo el valor probatorio del testimonio de la víctima del hecho como apto para desvirtuar la inicial presunción de inocencia que a todo acusado protege, sobre todo en delitos de agresión sexual que, de ordinario, tan solo son presenciados por las propias víctimas y teniendo en cuenta que, no aceptar esos testimonios alentaría, como ha recogido la jurisprudencia constitucional, un impunismo inaceptable y, de otra parte, que ya han pasado los tiempos en que se pudiera admitir la validez del principio "testis unus, testis nullus", exponente de una rigidez probatoria bien contrapuesta a la ausencia de prueba tasada que informa el sistema probatorio del proceso penal español».

${ }^{22}$ Adoptada por el Comité de Ministros del Consejo de Europa.

${ }^{23}$ Acordada por el Consejo de la Unión Europea.

${ }^{24}$ Informe COM (2009) de la Comisión de conformidad con el artículo 18 de la Decisión marco del Consejo, de 15 de marzo de 2001, relativa al estatuto de la víctima en el proceso penal (2001/220/JAI), emitido en Bruselas el día 20 de abril de 2009. 
2012/29/UE regulase de forma más amplia la victimización secundaria, a diferencia de las breves alusiones que se hacían en la Decisión 2001/220/JAI ${ }^{25}$.

La LEVD, que transpone la Directiva 2012/29/UE, traslada a España las preocupaciones europeas por evitar la victimización secundaria y, entre otras medidas, manifiesta la necesidad de reducir el número de declaraciones y reconocimientos médicos de las víctimas en general ${ }^{26}$. Sin embargo, esta aspiración, plasmada en el preámbulo de la Ley, sólo se materializa en el articulado de la norma con referencia a las declaraciones de las víctimas menores de edad y con discapacidad necesitadas de especial atención.

Por lo que se refiere al APLECrim 2020, se prohíbe la victimización secundaria en su artículo 103, rotulado "prohibición de la victimización secundaria», con el siguiente tenor literal:

1. Todas las autoridades que intervengan en el proceso penal adoptarán las medidas precisas para evitar que la víctima se vea sometida a situaciones que puedan causarle un sufrimiento innecesario o desproporcionado.

Igualmente velarán para que se reciba declaración a las víctimas sin dilaciones indebidas. La declaración de las víctimas y su reconocimiento médico únicamente se realizará cuando sea necesario a los fines de la investigación. No se repetirá su práctica salvo que resulte imprescindible a estos mismos fines.

2. La victima será tratada con pleno respeto a su dignidad en toda diligencia policial o actuación procesal que se realice. Recibirá un trato digno, habilitándose dependencias adecuadas al efecto y permitiendo que permanezca en ellas junto a su representante o persona que la acompañe.

En particular, las dependencias de las fiscalias y de los tribunales tendrán espacios de espera especialmente habilitados para acoger a las víctimas. En el acto del juicio oral se reservará un lugar especifico a la víctima y, en su caso, a su representante o persona que la acompañe.

25 Considerando 5 de la Decisión marco: «Es importante concebir y tratar las necesidades de la víctima de forma integrada y articulada, evitando soluciones parciales o incoherentes que puedan acarrear una victimación secundaria» (énfasis en cursiva añadido). Artículo 15 de la Decisión marco: "Los Estados miembros propiciarán la creación gradual, en el marco de las actuaciones en general y especialmente en los lugares en los que puede incoarse el proceso penal, de las condiciones necesarias para tratar de prevenir la victimación secundaria o evitar que la víctima se vea sometida a tensiones innecesarias. Para ello velarán en particular por que se dé una acogida correcta a las víctimas en un primer momento y por que se creen en dichos lugares condiciones adecuadas a la situación de la víctima" (énfasis en cursiva ańadido). A pesar de que en la traducción se ha elegido el término victimación -que no figura en el Diccionario de la Real Academia Espańola- la referencia se entiende hecha a la victimización secundaria.

26 Apartado vir del Preámbulo de la LEVD: «Para evitar la victimización secundaria en particular, se trata de obtener la declaración de la víctima sin demora tras la denuncia, reducir el número de declaraciones y reconocimientos médicos al mínimo necesario, y garantizar a la víctima su derecho a hacerse acompañar, no ya solo del representante procesal, sino de otra persona de su elección, salvo resolución motivada». 
Esto supone una novedad en relación con la actual LECrim, que, a pesar de que contiene algunas normas que tienen como finalidad evitar el riesgo de victimización secundaria ${ }^{27}$, no se hace referencia en ningún momento a este término. Ya en los Anteproyectos de Ley de Enjuiciamiento Criminal de los años 2011 y 2013 se establecía la prohibición de victimización secundaria, pero el nuevo APLECrim 2020 incluye algunas medidas adicionales que se resaltan en cursiva en la transcripción del artículo ut supra.

El día 25 de junio de 2021 entró en vigor la LOPIIA, que tiene como finalidad cumplir con el requerimiento realizado por el Comité de Derechos del Niño para que en Espańa se aprobara una ley integral sobre la violencia contra los niños y nińas ${ }^{28}$. Asimismo, la citada ley se inspira en los objetivos y metas de desarrollo sostenible fijados en la Agenda 2030, concretamente, en la meta 16.2: «Poner fin al maltrato, la explotación, la trata y todas las formas de violencia y tortura contra los niños ${ }^{29}$.

Tal y como se expone a continuación, el riesgo de sufrir victimización secundaria se incrementa en relación con las víctimas menores de edad, por lo que los funcionarios de la administración de justicia, los agentes de la policía y cualquier otro profesional que participe en el proceso penal deberán prestar especial atención a estas víctimas.

\subsection{LA VICTIMIZACIÓN SECUNDARIA DE LOS MENORES}

Hasta este momento me he referido al riesgo de victimización que fija la atención en el hecho delictivo; sin embargo, en este epígrafe me voy a centrar en el estudio de vulnerabilidad de la víctima, concretamente de las víctimas menores de edad $^{30}$. Landrove Díaz define a las víctimas especialmente vulnerables como aquéllas que «en función de circunstancias de muy diversa naturaleza, ofrecen una predisposición victimógena específica» y distingue dos factores de vulnerabilidad: personales

${ }^{27}$ La disposición final primera de la LEVD introduce modificaciones en la Ley de Enjuiciamiento Criminal (en adelante LECrim) para transponer la Directiva 2012/29/UE. Lo anterior supone que la redacción de algunos artículos de la LECrim esté inspirada en prevenir la victimización secundaria. Por ejemplo, los artículos 433, 448, 544 quinquies o 681 LECrim.

${ }^{28}$ Párrafo $100^{\circ}$ del apartado I del Preámbulo de la LOPIIA: «[...] el Comité de Derechos del Niño, con ocasión del examen de la situación de los derechos de la infancia en España en 2018, reiteró a nuestro país la necesidad de la aprobación de una ley integral sobre la violencia contra los nińos y nińas, que debía resultar análoga en su alcance normativo a la aprobada en el marco de la violencia de género».

${ }^{29}$ Esta meta se fija dentro del objetivo de desarrollo sostenible 16, que persigue como fin «Promover sociedades justas, pacíficas e inclusivas».

30 Siguiendo a Gómez Colomer, que entendía que «si se contempla desde el punto de vista del hecho, se habla de riesgo de victimización; si se contempla desde el punto de vista de sus efectos se habla de vulnerabilidad de la víctima». Gómez Colomer, J.L., Estatuto Jurídico de la Victima..., cit., p. 230 . 
y sociales ${ }^{31}$. Como factores personales puede citarse la edad o el estado psíquico del sujeto pasivo y como factores sociales la posición económica o el lugar de residencia.

La especial vulnerabilidad de las víctimas menores se reconoce, entre otras normas, en la Directiva 2011/36/ UE ${ }^{32}$, en la que se afirma que «los menores son más vulnerables que los adultos». Como ha señalado Magro Servet la vulnerabilidad de los menores a sufrir una segunda victimización se agrava porque no tienen la madurez suficiente para enfrentarse a la condición de víctima de un delito ni a una posterior confrontación con el autor del hecho delictivo ${ }^{33}$. Esta vulnerabilidad de los menores es todavía mayor cuando han sido víctimas de un delito contra la libertad e indemnidad sexuales. Así se ha reconocido por la jurisprudencia de la Sala 2. ${ }^{a}$ del TS, que ha declarado la especial vulnerabilidad de los menores víctimas de delitos de carácter sexual con especial referencia a los menores de corta edad ${ }^{34}$.

Esta especial vulnerabilidad de los menores víctimas de delitos ha generado una preocupación a nivel internacional y europeo por salvaguardar el interés del menor $^{35}$, que se trasladó a la LECrim con la aprobación de la Ley Orgánica 8/2006, de 4 de diciembre, por la que se modifica la Ley Orgánica 5/2000, de 12 de enero, reguladora de la responsabilidad penal de los menores. A pesar de que no parece la norma adecuada para reformar la LECrim, la disposición adicional primera de la Ley Orgánica 8/2006 modificó el artículo 433 LECrim otorgando al juez de instrucción la posibilidad de acordar la grabación de la declaración prestada por el menor en fase de instrucción.

${ }^{31}$ Landrove Díaz, G., Victimología, Tirant lo Blanch, Valencia, 1990, p. 42.

32 Dictada por el Parlamento Europeo y del Consejo de 5 abril de 2011, relativa a la prevención y lucha contra la trata de seres humanos y a la protección de las víctimas y por la que se sustituye la Decisión marco 2002/629/JAI del Consejo.

33 Magro Servet, V., «La victimización secundaria de los menores en el proceso penal», en Diario La Ley, n. ${ }^{\circ}$ 6282, 2005.

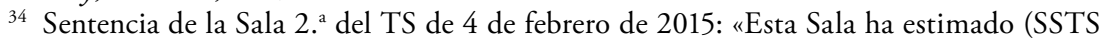
96/2009 de 10 de marzo, 743/2010, de 17 de junio , 593/2012, de 17 de julio y 19/2013, de 9 de enero, entre otras) que la previsión de imposibilidad de practicar una prueba testifical en el juicio oral, exigible para justificar la práctica anticipada de la prueba durante la instrucción, incluye los supuestos de menores victimas de delitos sexuales, con el fin de evitar los riesgos de victimización secundaria, especialmente importantes en menores de muy corta edad, cuando sea previsible que dicha comparecencia pueda ocasionar dańos psicológicos a los menores» (énfasis en cursiva añadido).

35 A modo de ejemplo pueden citarse las siguientes normas: la Convención sobre los Derechos del Niño, de 20 de noviembre de 1989; la Decisión marco 2001/220/JAI; la Directiva 2011/92/ UE del Parlamento Europeo y del Consejo de 13 de diciembre de 2011, relativa a la lucha contra los abusos sexuales y la explotación sexual de los menores y la pornografía infantil y por la que se sustituye la Decisión marco 2004/68/JAI del Consejo; y la Directiva 2012/29/UE. Asimismo, la protección de los menores frente al maltrato, la explotación, la trata y cualquier otra forma de violencia constituye una de las metas del $16 .^{\circ}$ Objetivo de Desarrollo Sostenible fijado en la Agenda 2030. El Gobierno de España hace referencia a un dato preocupante en relación con esta meta: «la cifra de niños entre 0 y 13 años víctimas de malos tratos en el ámbito familiar ha pasado de 13,53\% en 2010 a 26,16 en 2016». Puede consultarse en https://bit.ly/3cVG64H (último acceso 22 de marzo de 2021). 
A continuación, se analizarán las reformas operadas por la LEVD y LOPIIA en la regulación de la prueba testifical anticipada de las víctimas menores de edad, así como la nueva regulación propuesta en el APLECrim 2020.

\section{LA EXPLORACIÓN DE LOS MENORES EN LA FASE DE INSTRUCCIÓN}

Como ha señalado Serrano Masip, una de las situaciones que pueden causar al menor un grave perjuicio es su declaración en condición de víctima o testigo del hecho delictivo, dado que el relato de los hechos que ha padecido o presenciado puede provocar un proceso de victimización secundaria ${ }^{36}$. Actualmente, en el proceso penal español se obliga al juez a grabar la declaración de los menores-víctimas o testigos- practicada en fase de instrucción y se permite que éstas sean reproducidas en el juicio oral para que adquieran pleno valor probatorio. Sin embargo, como explicaré en líneas posteriores, la validez de esta declaración testifical está sujeta a una serie de requisitos y, además, debe apuntarse desde este momento que esta anticipación de la prueba es una excepción a la regla general de que los medios de prueba deben practicarse en el acto del juicio oral ${ }^{37}$.

\subsection{Contexto normativo}

La Decisión marco 2001/220/JAI establece que los Estados miembros propiciarán las condiciones necesarias para evitar el riesgo de "victimación" secundaria. Así, se regula en el artículo 8 de la referida Decisión que los Estados miembros deberán acordar las medidas necesarias para que las víctimas no sufran más daños como consecuencia de la práctica de la declaración testifical.

Esta normativa se transpone en España como consecuencia de la Sentencia de la Gran Sala del Tribunal de Justicia, de 16 de junio de 2005 (C-105/03, caso Pupino). La citada sentencia resuelve una petición de decisión prejudicial planteada por el juez de instrucción del Tribunal de Florencia (Italia) de acuerdo con el art. 35 del Tratado de la Unión Europea. La cuestión prejudicial tiene por objeto que la Gran Sala del Tribunal de Justicia se pronuncie sobre la interpretación de los artículos 2, 3 y 8 de la Decisión marco 2001/220/JAI. La duda interpretativa surge en relación con el carácter vinculante de los citados artículos, pues como sabemos las

36 Serrano Masip, M., «Una justicia europea adaptada al menor: exploración de menores víctimas o testigos en la fase preliminar del proceso penal», en InDret, 2013, p. 4.

37 Sentencia de la Sala 2. ${ }^{a}$ del TS de 19 de marzo de 2021: «En nuestro ordenamiento procesal, como recientemente ha recordado una vez más esta Sala en su sentencia 129/2007 de 24 de febrero, por regla general los medios de prueba con validez e idoneidad para desvirtuar la presunción de inocencia son los que se practican en el Juicio Oral bajo los principios de inmediación ante el mismo Tribunal que ha de juzgar; de contradicción entre las partes del proceso; y de publicidad». 
decisiones marco no tienen efecto directo ${ }^{38}$. La Gran Sala concluye que el órgano jurisdiccional debe interpretar el derecho nacional de acuerdo con las disposiciones de la decisión marco, siempre que no se vulneren los principios generales del derecho del estado miembro ${ }^{39}$. Así, los arts. 2,3 y 8 de la Decisión marco 2001/220/JAI imponen al juez nacional la obligación de utilizar los medios necesarios para proteger a las víctimas especialmente vulnerables.

Parece que el legislador -siguiendo esta exigencia supranacional- decidió modificar el artículo $433 \mathrm{LECrim}^{40}$ y reguló la posibilidad de grabar las declaraciones de los menores en fase de instrucción. Esta reforma proporciona al juez de instrucción una herramienta para proteger el interés del menor pues, si el juez decide acordar la grabación de la declaración, ésta podrá ser reproducida en el acto del juicio oral para que despliegue efectos probatorios sólo, eso sí, cuando el riesgo de victimización secundaria o las singulares condiciones personales del menor lo aconsejen. Por lo tanto, se abre la puerta a la realización de un acto de anticipación de prueba para salvaguardar el interés del menor, de manera que éste no tenga que volver a declarar en fase de juicio oral.

Posteriormente, con la entrada en vigor de la LEVD se modificó nuevamente el artículo 433 LECrim y, entre otras novedades, se impuso al juez la obligación de grabar la declaración de las víctimas menores o personas con la capacidad modificada judicialmente ${ }^{41}$. Además, con ocasión de la aprobación de la LEVD se

38 Artículo 34 UE, apartado 2, en la versión resultante del Tratado de Ámsterdam, que forma parte del título vi del Tratado de la Unión Europea: «b) adoptar decisiones marco para la aproximación de las disposiciones legales y reglamentarias de los Estados miembros. Las decisiones marco obligarán a los Estados miembros en cuanto al resultado que deba conseguirse, dejando, sin embargo, a las autoridades nacionales la elección de la forma y de los medios. No tendrán efecto directo» (énfasis en cursiva añadido).

39 «El órgano jurisdiccional nacional está obligado a tomar en consideración todas las normas del Derecho nacional y a interpretarlas, en todo lo posible, a la luz de la letra y de la finalidad de dicha Decisión marco».

40 Reforma introducida por la Ley Orgánica 8/2006, de 4 de diciembre por la que se modifica la Ley Orgánica 5/2000, de 12 de enero, reguladora de la responsabilidad penal de los menores.

41 Artículo 433 LECrim tras la LEVD: "Al presentarse a declarar, los testigos entregarán al secretario la copia de la cédula de citación. Los testigos mayores de edad penal prestarán juramento o promesa de decir todo lo que supieren respecto a lo que les fuere preguntado, estando el Juez obligado a informarles, en un lenguaje claro y comprensible, de la obligación que tienen de ser veraces y de la posibilidad de incurrir en un delito de falso testimonio en causa criminal. Los testigos que, de acuerdo con lo dispuesto en el Estatuto de la Víctima del Delito, tengan la condición de víctimas del delito, podrán hacerse acompañar por su representante legal y por una persona de su elección durante la práctica de estas diligencias, salvo que en este último caso, motivadamente, se resuelva lo contrario por el Juez de Instrucción para garantizar el correcto desarrollo de la misma. En el caso de los testigos menores de edad o personas con la capacidad judicialmente modificada, el Juez de Instrucción podrá acordar, cuando a la vista de la falta de madurez de la víctima resulte necesario para evitar causarles graves perjuicios, que se les tome declaración mediante la intervención de expertos y con intervención del Ministerio Fiscal. Con esta finalidad, podrá acordarse también que las preguntas se trasladen a la víctima directamente por los expertos o, incluso, excluir o limitar la presencia de las partes en el lugar de la exploración de la víctima. En estos casos, el Juez dispondrá lo necesario para 
reformó el artículo 730 LECrim para permitir la reproducción de las declaraciones de los menores en el acto del juicio oral, aunque esta modificación no supone una novedad, pues la jurisprudencia del TS ya había reconocido esta facultad al tribunal. Aunque habría sido deseable que la aprobación del Estatuto de la víctima solucionara los problemas planteados en torno a la anticipación de la prueba testifical de los menores, lo cierto es que todavía quedaban cuestiones pendientes, como la necesidad de reforma de los arts. 777.2 y 797.2 LECrim $^{42}$.

La LOPIIA ha modificado recientemente la regulación de la declaración testifical de los menores como prueba preconstituida. Así, esta ley suprime el párrafo cuarto del art. $433^{43}$ y el párrafo tercero del artículo 448 de la LECrim $^{44}$. Además, la disposición final primera de la LOPIIA introduce tres preceptos que tienen gran relevancia en la regulación del objeto de este trabajo. En primer lugar, se incorpora el artículo 449 bis LECrim, que regula la declaración de los testigos como la prueba preconstituida en los casos legalmente previstos y, además, se establece que deberá garantizarse el principio de contradicción durante la práctica de la declara-

facilitar a las partes la posibilidad de trasladar preguntas o de pedir aclaraciones a la víctima, siempre que ello resulte posible. El Juez ordenará la grabación de la declaración por medios audiovisuales». La cursiva añadida resalta las reformas que más interesan en este artículo.

42 Serrano Masip, M., «La incorporación al proceso penal español...», cit. p. 540. Esta autora entiende que para otorgar a la exploración de los menores la categoría de prueba anticipada «deberían haberse modificado los arts. 777.2 y 797.2 LECrim e incluir la minoría de edad, o una determinada franja de edad, en los presupuestos habilitadores de la práctica de prueba anticipada basándose en la imposibilidad objetiva de volver a testifical el menor en el juicio oral».

${ }^{43}$ Este precepto queda con el siguiente contenido: «Al presentarse a declarar, los testigos entregarán al secretario la copia de la cédula de citación. Los testigos mayores de edad penal prestarán juramento o promesa de decir todo lo que supieren respecto a lo que les fuere preguntado, estando el Juez obligado a informarles, en un lenguaje claro y comprensible, de la obligación que tienen de ser veraces y de la posibilidad de incurrir en un delito de falso testimonio en causa criminal. Los testigos que, de acuerdo con lo dispuesto en el Estatuto de la Víctima del Delito, tengan la condición de víctimas del delito, podrán hacerse acompañar por su representante legal y por una persona de su elección durante la práctica de estas diligencias, salvo que en este último caso, motivadamente, se resuelva lo contrario por el Juez de Instrucción para garantizar el correcto desarrollo de la misma. El Juez ordenará la grabación de la declaración por medios audiovisuales».

${ }^{44}$ Este artículo queda redactado como sigue: «Si el testigo manifestare, al hacerle la prevención referida en el artículo 446, la imposibilidad de concurrir por haber de ausentarse del territorio nacional, y también en el caso en que hubiere motivo racionalmente bastante para temer su muerte o incapacidad física o intelectual antes de la apertura del juicio oral, el Juez instructor mandará practicar inmediatamente la declaración, asegurando en todo caso la posibilidad de contradicción de las partes. Para ello, el Secretario judicial hará saber al reo que nombre abogado en el término de veinticuatro horas, si aún no lo tuviere, o de lo contrario, que se le nombrará de oficio, para que le aconseje en el acto de recibir la declaración del testigo. Transcurrido dicho término, el Juez recibirá juramento y volverá a examinar a éste, a presencia del procesado y de su abogado defensor y a presencia, asimismo, del Fiscal y del querellante, si quisieren asistir al acto, permitiendo a éstos hacerle cuantas repreguntas tengan por conveniente, excepto las que el Juez desestime como manifiestamente impertinentes. Por el Secretario judicial se consignarán las contestaciones a estas preguntas, y esta diligencia será firmada por todos los asistentes». 
ción ${ }^{45}$. En segundo lugar, se introduce el artículo 449 ter LECrim, que centra su atención en la declaración de las personas menores de catorce años o personas con discapacidad necesitadas de especial protección cuando intervengan como testigos en procedimientos judiciales que tengan por objeto el enjuiciamiento de un «delito de homicidio, lesiones, contra la libertad, contra la integridad moral, trata de seres humanos, contra la libertad e indemnidad sexuales, contra la intimidad, contra las relaciones familiares, relativos al ejercicio de derechos fundamentales y libertades públicas, de organizaciones y grupos criminales y terroristas y de terrorismo». Se establece en este precepto la obligación de la autoridad judicial de acordar en todo caso la práctica preconstituida de la declaración del menor o persona necesitada de especial protección. La práctica de la declaración podrá realizarse por medio de equipos psicosociales que sirvan como apoyo al órgano jurisdiccional; en este caso las preguntas propuestas por las partes serán trasladadas por este equipo de apoyo al menor, una vez que la autoridad judicial haya valorado la pertinencia de éstas. En el último párrafo del artículo 449 ter LECrim se dispone que su contenido también se aplicará en el enjuiciamiento de delitos leves ${ }^{46}$. En tercer lugar, se añade un artículo 703 bis LECrim, que regula la introducción de la grabación de la declaración en el acto del juicio oral ${ }^{47}$.

\subsection{LA DEClARACIÓN DE LOS MENORES EN FASE DE INSTRUCCIÓN: ¿UN ACTO DE PRUEBA ANTICIPADA O PRECONSTITUIDA?}

La jurisprudencia del TS ha establecido como regla general que «los medios de prueba con validez e idoneidad para desvirtuar la presunción de inocencia son los que se practican en el Juicio Oral bajo los principios de inmediación ante el mismo Tribunal que ha de juzgar; de contradicción entre las partes del proceso; y de publicidad ${ }^{48}$. Sin embargo, en ocasiones, la naturaleza irrepetible de los hechos

45 Véase el artículo 449 bis LECrim.

46 Véase el artículo 449 ter LECrim.

47 Véase el artículo 703 bis LECrim.

48 La sentencia de la Sala 2. ${ }^{\text {, }}$, de 10 de marzo 2009, es la primera resolución del TS que aplica la doctrina europea del caso Pupino y declara la validez de la anticipación de la declaración de los menores testigos o víctimas. Resulta cuando menos curioso que en este caso la grabación de la declaración de la menor fue propuesta por un inspector jefe de la brigada provincial de policía judicial que consultó por teléfono al juez de instrucción la posibilidad de realizar una «prueba preconstituida» para que la menor sólo testificase una vez. Parece que esta petición fue trasladada al juez de instrucción por la insistencia de los padres de la menor que -aconsejados por una psicóloga- pretendían evitar que el proceso penal causase todavía más daños a la menor. Artículo 741 LECrim. «El Tribunal, apreciando según su conciencia las pruebas practicadas en el juicio, las razones expuestas por la acusación y la defensa y lo manifestado por los mismos procesados, dictará sentencia dentro del término fijado en esta Ley. Siempre que el Tribunal haga uso del libre arbitrio que para la calificación del delito o para la imposición de la pena le otorga el Código Penal, deberá consignar si ha tomado en consideración los elementos de juicio que el precepto aplicable de aquél obligue a tener en cuenta» (énfasis en cursiva añadido). 
o la imposibilidad de ser trasladados al momento del juicio oral obligan al juez de instrucción -o incluso al Ministerio Fiscal o a la policía judicial- a llevar a cabo el aseguramiento de la prueba: (I) practicando el medio de prueba bajo la inmediación del juez de instrucción (prueba anticipada); (II) asegurando las fuentes de prueba que serán trasladadas al órgano de enjuiciamiento (prueba preconstituida) ${ }^{49}$.

En la Sentencia de la Sala 2. ${ }^{a}$ del TS, de 10 de marzo de 2009, se definen -en mi opinión erróneamente- los actos de prueba anticipada y preconstituida. En cuanto a la prueba anticipada, el TS entiende que la única diferencia entre ésta y la prueba practicada en el acto del juicio oral es la fase del proceso en que se realiza. Por lo tanto, la Sala 2. ${ }^{a}$ del TS ha definido la prueba anticipada como aquélla que se desarrolla en la fase de instrucción, pero ante el órgano de enjuiciamiento y con pleno respeto a los principios propios del juicio oral. Por el contrario, la prueba preconstituida se define como aquélla que se practica ante el juez de instrucción y, por tanto, supone un «sacrificio de la inmediación». Esta diferencia hace que el TS clasifique la grabación de la declaración de los menores en fase de instrucción como "prueba preconstituida" o "prueba anticipada en sentido impropio" ${ }^{50}$.

En mi opinión, siguiendo el profesor Gimeno Sendra, la diferencia entre la prueba preconstituida y la anticipada no se deriva de su realización por el órgano juzgador o de instrucción. Gimeno Sendra define ambos actos de aseguramiento de prueba como "auténticos actos de prueba, pero practicados por el Juez de Instrucción o excepcionalmente, en el caso de la prueba preconstituda por la policía judicial o el Ministerio Fiscal, y custodiados bajo la fe pública del Letrado de la Administración de Justicia». Para el citado autor la diferencia radica en el medio de prueba utilizado y en la posibilidad de que se realice, además de por el juez de instrucción, por el Ministerio Fiscal o la policía judicial. Así, entiende que los medios de prueba utilizados en la prueba anticipada son la testifical y la pericial, mientras que en la prueba preconstituida es la documental pública ${ }^{51}$.

Por todo lo expuesto, en este trabajo me referiré a la declaración de los menores en fase de instrucción como prueba anticipada, dado que los actos de anti-

${ }^{49}$ Gimeno Sendra, V., Derecho procesal penal, Castillo de Luna, Madrid, 2018, p. 322. Artículo 448 LECrim: «Si el testigo manifestare, al hacerle la prevención referida en el artículo 446, la imposibilidad de concurrir por haber de ausentarse del territorio nacional, y también en el caso en que hubiere motivo racionalmente bastante para temer su muerte o incapacidad física o intelectual antes de la apertura del juicio oral, el Juez instructor mandará practicar inmediatamente la declaración, asegurando en todo caso la posibilidad de contradicción de las partes [...]». La cursiva añadida pretende fijar la atención del lector en la referencia al juez de instrucción como encargado de realizar la prueba anticipada.

${ }^{50}$ La doctrina ha acogido la calificación dada por el TS. Véase, por ejemplo, BLANCO García, A.I., «El nuevo régimen de la declaración de testigos del Estatuto de la Víctima del delito: reforma del artículo 433 de la LECrim», en El proceso penal. Cuestiones fundamentales, Tirant lo Blanch, Valencia, 2017; Magro Servet, V., «Necesidad de la práctica de la prueba preconstituida con menores de edad en el Juzgado de Instrucción en los delitos contra la libertad sexual», en Diario La Ley, n. ${ }^{\circ}$ 6972, 2008.

51 Gimeno Sendra, V., Derecho procesal..., cit., p. 322. 
cipación de prueba se caracterizan por la realización del medio de prueba -como sucede con la grabación de la exploración de los menores en fase de instrucción-, a diferencia de la prueba preconstituida, que supone el aseguramiento de la fuente de prueba $^{52}$. Así, a pesar de que la anticipación de la declaración de los menores no se debe a la irrepetibilidad del hecho, entiendo que se trata de una imposibilidad objetiva impuesta por el legislador para proteger el interés del menor y evitar el riesgo de victimización secundaria ${ }^{53}$.

\subsection{El PRinCipio de CONTRAdicCión y la CÁMARA GESELL}

El principio de contradicción es «el fundamento del derecho de defensa» ${ }^{54}$. El Tribunal Constitucional (en adelante TC) ha declarado que las pruebas aptas para vincular a los órganos jurisdiccionales penales son las practicadas en el acto del juicio oral ante el juzgado o tribunal que dictará sentencia y bajo los principios de contradicción e inmediación ${ }^{55}$. La anterior afirmación ha sido matizada por el mismo tribunal en el sentido de que las diligencias sumariales que se han desarrollado cumpliendo con las garantías establecidas en la Constitución y la LECrim podrán valorarse por el órgano de enjuiciamiento siempre que puedan ser sometidas a contradicción en el acto de la vista ${ }^{56}$. Por lo tanto, se admite la validez de los actos de prueba anticipada y preconstituida, pues el TC ha manifestado que debe hacerse valer «la seriedad de lo actuado por los órganos encargados de la represión penal», máxime en un sistema que ampara la necesidad de protección de los bienes jurídicos y los derechos de los ciudadanos frente a posibles abusos ${ }^{57}$.

La jurisprudencia del TS ha declarado que la regla general debe ser la declaración de los menores en el acto del juicio oral ${ }^{58}$. Pero ha establecido una serie de

52 Ibidem. Gimeno Sendra señala que «[...] el aseguramiento de la prueba es una actividad del Juez de Instrucción que comprende dos cometidos concretos, bien la práctica del acto de prueba, en cuyo caso nos encontramos ante un supuesto de prueba instructora anticipada, bien la guarda o custodia de ambas fuentes de prueba a través de actos de prueba preconstituida».

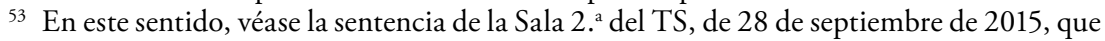
equipara la prueba testifical anticipada de un testigo que no podrá acudir al juicio oral con la anticipación de la declaración de los menores por la existencia de un riesgo de victimización.

54 Gimeno Sendra, V., Constitución y proceso, Tecnos, Madrid, 1998, p. 88.

55 Véase en este sentido SSTC 217/1989, de 21 de diciembre; 161/1990, de 19 de octubre, 303/1993, de 25 de octubre; 12/2002, de 28 de enero; y 280/2005 de 7 de noviembre. Además, el artículo 449 bis LECrim establece que «la autoridad judicial garantizará el principio de contradicción en la práctica de la declaración» (énfasis en cursiva añadido).

${ }^{56}$ En este sentido, SSTC 10/1992, de 16 de enero; y 187/2003, de 27 de octubre.

57 STC 56/2010, de 4 de abril: «Un sistema que pondere adecuadamente tanto la necesidad social de protección de bienes jurídicos esenciales, como el haz de garantías frente a posibles abusos de los ciudadanos, con independencia de su posición, ha de estar en condiciones de hacer valer la seriedad de lo actuado por los órganos encargados de la represión penal; siempre que lo actuado lo haya sido con pleno respeto a aquellas garantías».

58 Sentencia de la Sala 2. ${ }^{\text {a }}$ del TS, de 14 de octubre de 2014. 
presupuestos para que la grabación de la declaración del menor en fase de instrucción tenga valor probatorio: (I) la existencia de riesgo para la salud psíquica de los menores, que deberá estar acreditada, por ejemplo, por un informe psicológico; (II) la ponderación de la edad y madurez del menor; (III) la imposibilidad de adoptar otras medidas que eviten la victimización secundaria; (Iv) la motivación por el juez o magistrado de la necesidad de anticipar la prueba testifical; (v) la reproducción de la grabación de la declaración del menor en el acto del juicio oral ${ }^{59}$. Estos presupuestos, junto con la presencia del juez de instrucción, el Ministerio Fiscal y el letrado del investigado en la declaración prestada, permiten que no pueda apreciarse vulneración del derecho a un proceso con todas las garantías ${ }^{60}$.

Tras la entrada en vigor de la LOPIIA deberá acordarse la declaración testifical de los menores de catorce ańos y personas con discapacidad necesitadas de especial protección en los delitos «de homicidio, lesiones, contra la libertad, contra la integridad moral, trata de seres humanos, contra la libertad e indemnidad sexuales, contra la intimidad, contra las relaciones familiares, relativos al ejercicio de derechos fundamentales y libertades públicas, de organizaciones y grupos criminales y terroristas y de terrorismo" ${ }^{61}$.

La excepcionalidad de la declaración de los menores como prueba anticipada se debe a que el principio de contradicción sólo puede garantizarse plenamente en el juicio oral; por lo tanto, sólo se admite la limitación de la contradicción para proteger el interés superior del menor cuando existan razones fundadas de la existencia de un riesgo de victimización secundaria ${ }^{62}$.

Como ha señalado Moreno Catena, para que exista una contradicción procesal efectiva es necesario que la defensa pueda no sólo proponer y practicar los medios de prueba pertinentes para su defensa, sino también que intervenga en el desarrollo de la prueba para desacreditar la fiabilidad del testigo o poner de manifiesto contradicciones en su testimonio ${ }^{63}$. En las declaraciones sumariales de los menores la contradicción se garantiza en dos ocasiones: (I) en la fase de instrucción, pues las partes podrán plantear al menor -por medio del perito psicológico- las preguntas

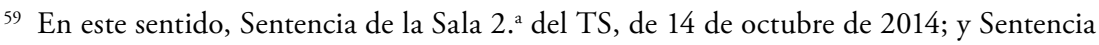

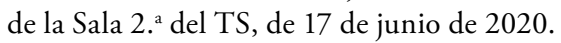

${ }^{60}$ Sentencia de la Sala 2. ${ }^{\text {a }}$ del TS, de 10 de marzo de 2009: «En definitiva en este caso la prueba preconstituida se hizo a presencia del Juez de Instrucción, asistido del Secretario Judicial, y con la presencia del Ministerio Fiscal y del letrado del imputado, en la fase instructora del procedimiento abreviado, quedando por ello cumplida la exigencia del principio de contradicción establecida por el art. 772.2 de la LECr».

${ }^{61}$ Artículo 449 ter LECrim introducido por la LOPIIA, que entró en vigor el 26 de junio de 2021.

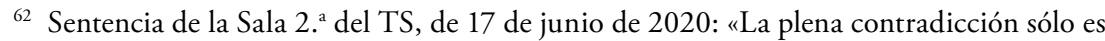
posible en el juicio oral, pues sólo en ese momento se dispone de la hipótesis acusatoria formalizada y se conoce el contenido de los elementos investigativos empleados para construirla, así como el listado de los medios de prueba propuestos para verificarla».

${ }^{63}$ Moreno Catena, V.M., «La protección de los testigos y peritos en el proceso penal español», en Revista penal, n. ${ }^{\circ}$ 4, 1999, p. 65. 
que el juez estime pertinentes; (II) en la fase del juicio oral con la reproducción de la declaración del menor las partes podrán debatir la verosimilitud del testimonio del menor ${ }^{64}$. Una de las herramientas utilizadas para garantizar que tanto el juez como las partes puedan presenciar la declaración de los menores y plantear al menor las preguntas que consideren es la denominada cámara Gesell. Esta cámara, también denominada de observación, permite que los menores declaren en una sala, mientras que las partes y el juez están situados en una sala contigua separada por un espejo que les permite observar al menor y al mismo tiempo impide que el menor se percate de su presencia ${ }^{65}$.

Aunque algunos juzgados y tribunales españoles ya cuentan con unas instalaciones que cumplen con las condiciones de la cámara Gesell ${ }^{66}$, lo cierto es que destinar dos salas de un juzgado o tribunal -que habitualmente no disponen de instalaciones suficientes- puede suponer un problema para implementar el uso de esta técnica. Tal y como apuntaba al comienzo de este trabajo, los medios tecnológicos de grabación de imagen y sonido pueden servir de gran ayuda para proteger el interés del menor. El uso de equipos de grabación de imagen y sonido facilita a los juzgados y tribunales la toma de declaración a través de un sistema de cámara de observación, pues el uso de una cámara web en la sala en la que está situado el menor y un ordenador en cualquier otra sala del juzgado -que no tiene por qué situarse de forma contigua a la sala donde se encuentra el menor-permitirá que las partes y el juez presencien en tiempo real la declaración del menor.

La pregunta que se plantea a continuación es la siguiente: ¿cómo trasladarán las partes y el juez las preguntas al psicólogo? Pues bien, la tecnología ofrece también una solución a este problema. El uso de un auricular inalámbrico por el psicólogo será el medio para que el juez trasmita al psicólogo las preguntas que tanto él mismo como las partes quieran plantear al menor, así se garantiza también que el juez valore previamente la procedencia de las cuestiones propuestas por las partes.

La grabación de la prueba anticipada será reproducida en el acto del juicio oral, de modo que se someta al debate de las partes en presencia del tribunal sentenciador y se garantice el principio de inmediación y contradicción ${ }^{67}$. Parece que

${ }^{64}$ Cubillo López, I.J., La protección de los testigos en el proceso penal, Aranzadi, Navarra, 2009, pp. 212-213.

65 Sempere Faus, S., «La grabación audiovisual de la declaración del menor de edad: la prueba preconstituida y la eficacia de la cámara Gesell en la reducción de la victimización secundaria», en Revista General de Derecho procesal, n. ${ }^{\circ} 48,2019$, p. 38.

${ }^{66}$ Por ejemplo, la Ciudad de la Justicia de Las Palmas de Gran Canaria (https://bit.ly/2OYcrA7); los juzgados de Arrecife en Lanzarote (https://bit.ly/38XBfie); o los juzgados de Móstoles, en Madrid (https://bit.ly/3r1U1v3). Último acceso a los enlaces: 22 de marzo de 2021. En este sentido, Sempere Faus, S., «La grabación audiovisual de la declaración del menor..., cit.

${ }_{67}$ Cubillo López, I.J., La protección de los testigos..., cit., p. 225, en Calderón CuaDRADO, M.P., La encrucijada de una justicia penal tecnológicamente avanzada. Sobre la grabación de las vistas, los recursos y la garantía de la inmediación, La Ley, Madrid, 2011, p. 131, la autora -en relación con la reproducción del medio de prueba en fase de recurso- entiende que no se trata de «un verdadero juicio inmediato", pues la actividad probatoria no se repite en presencia del órgano que conoce 
- como ha señalado el TS - no debe existir una confrontación entre el principio de contradicción y el derecho de defensa del acusado con la protección de los menores frente al riesgo de victimización secundaria ${ }^{68}$.

\subsection{La VAlideZ De LA PRUEba ANTICIPADA PARA DESVIRTUAR EL DERECHO A LA PRESUNCIÓN DE INOCENCIA}

Gimeno Sendra acogía de forma efusiva la consagración del derecho a la presunción de inocencia en la Constitución Española de 1978, pues la situación anterior a esta norma fundamental otorgaba al imputado una «presunción de culpabilidad, de la cual había de desprenderse en el momento del juicio oral» ${ }^{69}$. El derecho fundamental a la presunción de inocencia está presente en todas las fases del proceso penal; sin embargo, en el acto de juicio oral adquiere especial importancia, pues las partes acusadoras deben proponer la práctica de medios de prueba suficientes para desvirtuar la presunción de inocencia del acusado.

El TC ha declarado que el derecho a la presunción de inocencia «se configura en tanto que regla de juicio y desde la perspectiva constitucional, como el derecho a no ser condenado sin pruebas de cargo válidas, lo que implica que exista una mínima actividad probatoria, realizada con las garantías necesarias, referida a todos los elementos esenciales del delito y que de la misma quepa inferir razonablemente los hechos y la participación del acusado en ellos» ${ }^{70}$. Las declaraciones de los menores en fase de instrucción suscitan dos cuestiones en relación con el derecho a la presunción de inocencia: (I) la testifical de la víctima como única prueba de cargo; (II) la práctica de la prueba en la fase de instrucción.

del recurso. Así, entiende que la reproducción de la grabación podría comportar «una inmediación virtual». Lo mismo sucede en la reproducción de la prueba testifical anticipada, pues el órgano de enjuiciamiento puede presenciar de forma mediata la práctica de la prueba, pero no podrá realizar las preguntas que estime necesarias al testigo-víctima.

${ }^{68}$ Véase la sentencia de la Sala 2. ${ }^{2}$ del TS, de 26 de noviembre de 2019, en Alonso Rimo, A., «Medidas de protección de los intereses de las víctimas: su fundamentación desde un punto de vista penal», en Estudios de Victimología. Actas del I Congreso español de victimología, Tirant lo Blanch, Valencia, 2005, p. 53, el autor afirma que «una comprensión del Derecho -que es, según creo, la que resulta más respetuosa con nuestro modelo de Estado constitucional- en virtud de la cual aquél debe limitarse a "ordenar la convivencia externa de los ciudadanos del modo menos gravoso posible para sus derechos y libertades", no ha de resultar problemático afirmar -haciendo una interpretación de dicha concepción kantiana del Derecho en clave integradora de la víctima- que deben respetarse también tales exigencias (es, decir, esos mismos derechos y libertades) en relación asimismo con la víctima». Por lo tanto, los derechos del autor del delito y la víctima deben alcanzar un equilibrio no sólo en el derecho procesal, sino también como señala Alonso Rimo en el derecho penal (énfasis en cursiva añadido).

${ }^{69}$ Gimeno Sendra, V., Constitución y..., cit., p. 109.

70 Véase, STC 123/2006, de 24 de abril. 
(I) En cuanto al testimonio de la víctima como única prueba de cargo -como ya he dicho en páginas anteriores ${ }^{71}-$, el TS ha establecido que puede valorarse como prueba de cargo suficiente, siempre que el tribunal no aprecie razones que resten credibilidad al testimonio de la víctima. Para la determinación de la verosimilitud de la declaración de la víctima el TS ha establecido los siguientes criterios orientativos: (I) inexistencia de enemistad, resentimiento, ánimo de venganza, enfrentamiento o cualquier interés ajeno a la finalidad del proceso; (II) existencia de datos de carácter objetivo que corroboren la versión de la víctima; y (III) persistencia en la incriminación. Respecto a este último criterio, en la Sentencia de la Sala 2. ${ }^{a}$ del TS, de 13 de noviembre de 2003 , se señala que el acusado debe tener la oportunidad de evidenciar las contradicciones o ambigüedades de la declaración de la víctima.

(II) Esta última exigencia guarda estrecha relación con la práctica de la prueba en la fase de instrucción. Para garantizar el derecho a la presunción de inocencia no sólo debe existir un testimonio verosímil, sino que además debe permitirse a la defensa del acusado poner en duda dicha verosimilitud. A pesar de que la STC 31/1981, de 28 de julio, precisó que las pruebas que debe valorar el órgano enjuiciador son las practicadas en el acto del juicio oral, la prueba anticipada, como es sabido, es una excepción a esta regla general. La doctrina del TS ha establecido los siguientes requisitos para que la prueba testifical anticipada consistente en la declaración del menor sea una prueba de cargo suficiente para desvirtuar el derecho a la presunción de inocencia: (I) la imposibilidad de comparecencia del menor en el juicio oral, que, como hemos visto, se acredita por el informe pericial que ponga de manifiesto el riesgo de victimización; (II) la declaración debe prestarse ante el juez de instrucción; (III) el principio de contradicción debe respetarse con la presencia de la defensa; (Iv) la grabación de la declaración debe ser reproducida en el acto de juicio oral ${ }^{72}$.

Por lo tanto, la protección del interés superior del menor permite que la prueba testifical anticipada - practicada conforme a las exigencias que ha establecido la jurisprudencia del TS- se constituya como prueba de cargo suficiente para desvirtuar el derecho a la presunción de inocencia.

\subsection{LA REgUlaCión DE LA DEClARACIÓN DE LAS VÍCTIMAS MENORES DE EDAD EN EL APLECRIM 2020}

Como ya he apuntado, la LOPIIA ha reformado la regulación de la prueba testifical anticipada cuando las víctimas son menores de 14 años o personas necesitadas de especial protección; no obstante, el APLECrim 2020 también propone

71 V. supra, 1.1.

72 La Sentencia de la Sala 2. ${ }^{a}$ del TS, de 28 de septiembre de 2015, fija estos criterios en relación con la prueba testifical anticipada de un testigo que se prevé no podrá acudir a declarar al acto del juicio oral, pero la Sala 2. ${ }^{a}$ declara que serán de aplicación también a los supuestos en que la anticipación se realice por la existencia de un riesgo de victimización secundaria. 
una regulación novedosa de la declaración de los menores en la fase de instrucción y su posterior reproducción en el acto del juicio oral. Tras la exigencia del Comité de Derechos del Niño en el año 2018 para aprobar una ley integral sobre violencia contra niños y niñas, parece que el legislador aprovechó la LOPIIA para modificar e introducir algunos preceptos con respecto a la regulación de la declaración anticipada de los menores. Las reformas introducidas por la LOPIIA ya han sido analizadas, por lo que este apartado se centrará en el análisis de la propuesta de regulación del APLECrim 2020, pues si este anteproyecto se convierte en Ley la principal consecuencia será una nueva modificación de la prueba testifical anticipada como instrumento para evitar la victimización secundaria de los menores.

Así, en el capítulo v del APLECrim 2020, rotulado «el estatuto de la víctima en el proceso penal», se otorga la condición de víctima en situación de especial vulnerabilidad a aquélla que por su edad, discapacidad o enfermedad no puede «someterse directamente al examen contradictorio de las partes» ${ }^{73}$. En este mismo capítulo se establece la prohibición de victimización secundaria y se dispone que la declaración de las víctimas debe llevarse a cabo sin dilación y, en la medida de lo posible, una única vez ${ }^{74}$.

Tal y como ha señalado Montesinos García, el proceso de victimización secundaria como consecuencia de la relación de la víctima con la administración de justicia es tan evidente que no sólo se ha acuñado esta expresión para referirla ${ }^{75}$, sino que además el APLECrim 2020 impone a todas las autoridades que intervengan en el proceso penal la adopción de medidas para prevenir el riesgo de victimización secundaria.

En relación con la declaración de los menores de edad o personas con discapacidad, el legislador establece una serie de especialidades en los arts. 600 a 602 del APLECrim 2020. Así, la declaración testifical de los menores -o personas con la capacidad modificada judicialmente- se realizará de forma reservada con la presencia de un perito experto en psicología "del testimonio»" ${ }^{76}$. El juez podrá acordar que la declaración se practique sin la presencia inmediata del Ministerio Fiscal ni de las partes, pero deberá garantizarse que puedan presenciarla de forma mediata.

73 Artículo 102 del APLECrim 2020: «Tienen en todo caso esta condición las víctimas que por razón de su edad, enfermedad o discapacidad no puedan someterse directamente al examen contradictorio de las partes».

${ }^{74}$ Artículo 103.1 párrafo segundo del APLECrim 2020: «Igualmente velarán para que se reciba declaración a las víctimas sin dilaciones indebidas. La declaración de las víctimas y su reconocimiento médico únicamente se realizará cuando sea Anteproyecto de Ley de Enjuiciamiento Criminal necesario a los fines de la investigación. No se repetirá su práctica salvo que resulte imprescindible a estos mismos fines».

${ }^{75}$ Montesinos García, A., «La lectura o reproducción de las declaraciones sumariales de los menores en el juicio oral", en El proceso penal. Cuestiones fundamentales, Tirant lo Blanch, Valencia, 2017, p. 239.

${ }^{76}$ El cumplimiento de la exigencia de la participación de un perito psicólogo del testimonio dependerá de la disponibilidad del juzgado, así que puede que en la práctica participe en la declaración un psicólogo sin dicha especialidad. 
La presencia mediata del juez y las partes acusadoras podrá tener lugar por medio de las siguientes técnicas: (I); la declaración del menor en una sala que permita a las partes y al juez observar lo que sucede a través de un cristal efecto espejo (cámara Gesell); o (II) la reproducción de imagen y sonido en tiempo real en otra sala del juzgado o tribunal. Esta presencia "mediata» permite que el menor no sienta la presión del MF o las partes y garantiza el principio de contradicción, pues las partes pueden plantear al juez las preguntas que estimen oportunas para que éste las transmita al perito psicólogo.

El artículo 600 del APLECrim 2020 establece que la declaración del menor será siempre grabada para que, si la edad del menor o circunstancias personales del testigo lo aconsejan, pueda reproducirse tal grabación en el acto del juicio oral. Además, añade que podrá reproducirse también la grabación de la declaración en el acto del juicio oral cuando por el tiempo transcurrido se presuma que la «calidad informativa del testimonio" se ha visto mermada.

La protección del interés del menor en el APLECrim 2020 se cierra con la regulación de algunas particularidades para aquellos supuestos en que la víctima menor de edad finalmente deba declarar en el acto del juicio oral: (I) la presencia de representante legal del menor o persona con discapacidad; (II) cuando el menor tenga menos de 16 años se evitará la confrontación visual con el acusado; (III) cuando sea posible, el menor prestará declaración sin estar presente en la sala de vistas; (Iv) el interrogatorio se realizará por el presidente del tribunal, que trasladará las preguntas de las partes ${ }^{77}$.

\section{CONCLUSIONES}

La grabación de la declaración de los menores en la fase de instrucción es una medida eficaz para reducir el riesgo de victimización secundaria, pues así se permite que ésta pueda reproducirse en el acto del juicio oral para que adquiera pleno valor probatorio. En mi opinión, esta declaración debe clasificarse como un acto de prueba anticipada, puesto que en la fase de instrucción se ha practicado el

77 Artículo 672 del APLECrim 2020: «Cuando los testigos menores de edad y las personas con discapacidad en situación de vulnerabilidad hayan de prestar declaración en el juicio oral, será de aplicación el régimen establecido para la declaración de testigos con las siguientes salvedades: a) La declaración se prestará con la asistencia del representante legal del menor o de quien integre la institución de apoyo de la persona con discapacidad, conforme a lo establecido en los artículos 469 y 470 de esta ley. b) La declaración de los testigos menores de dieciséis años siempre se llevará a cabo evitando la confrontación visual con el acusado. c) Cuando las condiciones de la persona que haya de declarar lo requieran, la declaración se realizará utilizando las tecnologías de la comunicación que permitan que el testigo preste declaración en dependencias judiciales, sin estar presente en la sala de vistas. d) El testigo será interrogado únicamente por el presidente del tribunal, pudiendo las partes solicitar que realice las preguntas adicionales que consideren necesarias. No obstante, el presidente permitirá que las partes realicen las preguntas directamente si de ello no se deriva perjuicio alguno para el testigo». 
medio de prueba, a diferencia de los actos de prueba preconstituida, en los que el juez de instrucción se limita a asegurar la fuente de prueba. La otra cuestión que plantea dudas en relación con la clasificación como prueba anticipada de la exploración sumarial del menor es la inexistencia de irrepetibilidad del hecho; no obstante, debe concluirse que se trata de una imposibilidad objetiva impuesta por el legislador para proteger el interés del menor y, en consecuencia, de la sociedad.

En cuanto al interés de la sociedad, debe señalarse que el hecho de que las relaciones con la administración de justicia puedan causar perjuicios a las víctimas parece contrario a la idea de justicia que GUASP desdobla en dos facetas: la satisfacción y el perfeccionamiento ${ }^{78}$. Pues bien, en mi opinión, el legislador debe proporcionar a las autoridades que participan en el proceso penal los instrumentos necesarios para reducir el riesgo de victimización secundaria. Parece que éste es el objetivo de la introducción de la prohibición de la victimización secundaria en el APLECrim, así como de la regulación más detallada de las declaraciones de las víctimas menores de edad. No obstante, tras la entrada en vigor de la LOPIIA, parece que la normativa española ha cumplido con las exigencias europeas en relación con la protección del interés superior del menor y está más cerca de lograr la referida satisfacción social.

Recibido: marzo de 2021; ACEPTAdo: abril de 2021

${ }^{78}$ Guasp, J., Derecho, Madrid, 1971, pp. 327-328 


\section{BIBLIOGRAFÍA}

Alonso Rimo, A., «Medidas de protección de los intereses de las víctimas: su fundamentación desde un punto de vista penal», en Estudios de Victimología. Actas del I Congreso español de victimología, Tirant lo Blanch, Valencia, 2005.

Barona Vilar, A., "Cuarta revolución industrial (4.0) o ciberindustria en el proceso penal: revolución digital, inteligencia artificial y el camino hacia la robotización de la justicia», en Revista jurídica digital UANDES, n. ${ }^{\circ} 1,2019$.

Borges Blázquez, R., «El sesgo de la máquina en la toma de decisiones en el proceso penal», en IUS ET SCIENTIA: Revista electrónica de Derecho y Ciencia, n. ${ }^{\circ}$ 2, 2020.

Bueno de Mata, F., «Macrodatos, inteligencia artificial y proceso: luces y sombras», en Revista General de Derecho Procesal, n. ${ }^{\circ}$ 51, 2020.

Blanco García, A.I., «El nuevo régimen de la declaración de testigos del Estatuto de la Víctima del delito: reforma del artículo 433 de la LECrim», en El proceso penal. Cuestiones fundamentales, Tirant lo Blanch, Valencia, 2017.

Calderón Cuadrado, M.P., La encrucijada de una justicia penal tecnológicamente avanzada. Sobre la grabación de las vistas, los recursos y la garantía de la inmediación, La Ley, Madrid, 2011.

Cubillo López, I.J., La protección de los testigos en el proceso penal, Aranzadi, Navarra, 2009.

Gimeno Sendra, V., Constitución y proceso, Tecnos, Madrid, 1998.

Gimeno Sendra, V., Derecho procesal penal, Castillo de Luna, Madrid, 2018.

Gómez Colomer, J.L., Estatuto Jurídico de la Victima del delito. La posición jurídica de la víctima de delito ante la justicia penal. Un análisis basado en el Derecho comparado y en las grandes reformas españolas que se avecinan, Aranzadi, Navarra, 2014.

Guasp, J., Derecho, Madrid, 1971.

Landrove Díaz, G., Victimología, Tirant lo Blanch, Valencia, 1990.

Landrove Díaz, G., "La víctima y el juez», en Victimología: VIII Cursos de Verano en San Sebastián, Universidad del País Vasco, 1990.

Magro Servet, V., «Necesidad de la práctica de la prueba preconstituida con menores de edad en el Juzgado de Instrucción en los delitos contra la libertad sexual», en Diario La Ley, n. ${ }^{\circ} 6972,2008$.

Magro Servet, V., «La victimización secundaria de los menores en el proceso penal», en Diario La Ley, n. ${ }^{\circ}$ 6282, 2005.

Montesinos García, A., «La lectura o reproducción de las declaraciones sumariales de los menores en el juicio oral», en El proceso penal. Cuestiones fundamentales, Tirant lo Blanch, Valencia, 2017.

Moreno Catena, V.M., «La protección de los testigos y peritos en el proceso penal español», en Revista penal, n. ${ }^{\circ}$ 4, 1999.

Morillas Fernández, D.L., "La victimización penitenciaria», en Revista Internacional de Doctrina y Jurisprudencia, n. ${ }^{\circ}$ 14, 2016.

Morillas Fernández, D.L., Patró Hernández, R.M. y Aguilar Cárceles, M.M., Victimologia: un estudio sobre la victima y los procesos de victimización, Dykinson, Madrid, 2014. 
Sempere Faus, S., «La grabación audiovisual de la declaración del menor de edad: la prueba preconstituida y la eficacia de la cámara Gesell en la reducción de la victimización secundaria», en Revista General de Derecho procesal, n. ${ }^{\circ} 48,2019$.

Serrano Masip, M., «La incorporación al proceso penal español de la normativa UE sobre el interrogatorio o la exploración de la víctima menor de edad», en Delitos contra la libertad e indemnidad sexual de los menores, Aranzadi, Navarra, 2015.

Serrano Masip, M., "Una justicia europea adaptada al menor: exploración de menores víctimas o testigos en la fase preliminar del proceso penal», en InDret, 2013. 
